\title{
Human Cell Surface Receptors as Molecular Imaging Candidates for Metastatic Prostate Cancer
}

\author{
Isis C. Sroka ${ }^{1,6}$, Gerald D. Pond ${ }^{2}$, Raymond B. Nagle ${ }^{3,6}$, Frank Porreca ${ }^{1}$, Tamara King ${ }^{1}$, \\ Gary Pestano ${ }^{7}$, Bernard W. Futscher ${ }^{4,6}$, Jaime M. Gard ${ }^{6}$, Janice Riley ${ }^{7}$ \\ Ubaradka G. Sathyanarayana ${ }^{7}$ and Anne E. Cress ${ }^{5,6, *}$
}

Departments of Pharmacology ${ }^{1}$, Radiology ${ }^{2}$, Pathology ${ }^{3}$, Pharmacology and Toxicology ${ }^{4}$, Cell Biology and Anatomy ${ }^{5}$, The Arizona Cancer Center ${ }^{6}$, University of Arizona, Tucson, AZ 85724 and Ventana Medical Systems ${ }^{7}$, Tucson, AZ 85704

\begin{abstract}
Existing clinical imaging procedures lack sensitivity and specificity in detecting early prostate cancer bone metastatic lesions. In this study, we developed a highly reproducible bone metastasis xenograft model and identified possible molecular imaging candidates for detecting early bone metastatic lesions. Bone trophic human prostate cells (PC-3B1) were isolated and characterized for their ability to reach bone after intracardiac injection into SCID mice. The appearances of skeletal metastases were evaluated using digital radiographic imaging and confirmed by necropsy and histology. The PC-3B1 cells retain a bone homing phenotype after long term propagation in tissue culture and exhibit progressive bone lesions within 3 weeks following intracardiac injection. Comparative transcription signatures of PC-3 and PC-3B1 cells were determined using a cancer specific microarray and confirmed by RT-PCR analysis. The analysis identified increased expression of four cell surface molecules in PC-3B1 cells that may be suitable as molecular imaging candidates to detect bone micro metastases.
\end{abstract}

\section{INTRODUCTION}

Recent advancements in the field of molecular imaging have led to innovative techniques for imaging biological processes in living subjects. These methods have high specificity and sensitivity and are useful in imaging specific cellular and molecular events related to disease processes [1]. Magnetic resonance spectroscopy imaging (MRSI) has shown promise in the evaluation of clinical staging of prostate cancer when it is combined with magnetic resonance imaging (MRI) [2-4]. Although MRSI can significantly improve clinical assessment and plays a confirmatory role in the identification of the disease during initial staging [2-5], the modality is not yet accurate or sensitive for detection of prostate cancer bone metastatic lesions.

The use of novel MRSI nanoparticle contrast agents to target specific cellular processes holds promise for increasing sensitivity and specificity in prostate cancer imaging. Superparamagnetic iron oxide nanoparticles (SPION) directed at the prostate-specific membrane antigen (PMSA) used to detect prostate cancer cells represents the first in an expanding line of MR contrast agents [4, 6, 7]. Additional nanoparticles have been created that are specific for targeting cell surface molecules such as E-selectin, Her2/neu, 9.2.27 proteoglycan sulfate and integrin $\alpha \mathrm{V} \beta 3$ [8-10]. These cell surface imaging candidates provide enhanced specificity in that magnetic nanoparticles directed at transmembrane receptors highly expressed in tumors will be less likely

*Address correspondence to this author at the The Arizona Cancer Center, 1515 N. Campbell Avenue, Tucson, AZ 85724; Tel: (520) 626-7553;

Fax: (520) 626-4979; E-mail: acress@azcc.arizona.edu to collect in off target sites within the body [8]. In prostate cancer, specific cell adhesion receptors called integrins, are persistently expressed on the cell surface of invasive prostate tumor cells in metastatic lesions [11]. While the $\alpha 6 \beta 1$ integrin and its novel variant $\alpha 6 \mathrm{p} \beta 1[12,13]$ are excellent targets for detecting or preventing metastatic prostate cancer [14], additional cell surface molecules may be equally strong imaging candidates.

Murine xenograft models of human prostate carcinoma bone metastasis have been established using direct injection of cancer cell lines into the left ventricle to characterize prostate tumor cell interactions with the bone microenvironment $[15,16]$. The purpose of our study was to establish a human bone trophic prostate cancer cell line using a xenograft model and to use these cells to identify potential membrane specific target genes suitable for molecular imaging probe development specific for prostate cancer bone metastasis.

\section{MATERIALS AND METHODS}

\section{Prostate Cancer Cell Lines}

The PC-3 cell line was obtained from American Type Tissue Collection (ATCC, Manassas, VA) and grown using standard tissue culture conditions as previously described [17]. The PC-3B1 cells were isolated from the bone marrow of SCID mice that had been injected six weeks previously with the PC-3 cell line [14]. Isolation of the cells was guided by radiographic detection of the lesion and flushing the bone cavity with phosphate buffered saline (PBS). The resulting mixture was placed on laminin-332 coated tissue culture dishes and grown to confluency using optimal growth conditions for PC-3 cells. The resulting PC-3B1 cells were immortal and maintained in tissue culture for 5 weeks, 
formed tumors in SCID mice, contained epithelial morphology, and expressed epithelial markers such as cytokeratin and $\alpha 6$ integrin [14].

\section{Animal Injections and Imaging}

All animal experiments were performed using the facilities and staff of the Experimental Mouse Shared Service located at the Arizona Cancer Center. The mice were injected, weighed and observed for critical signs of morbidity twice weekly. Animals were euthanized if they showed signs of pain/suffering including rapid, slow, and shallow or labored breathing, rapid weight loss, anorexia, hunched posture, hypo- or hyperthermia, cachexia, diarrhea or constipation, paralysis or impaired ambulation, lethargy, and/or nasal/ocular discharge or if micro fractures were scored on the radiographic analysis. Animals were euthanized via $\mathrm{CO}_{2}$ inhalation. All procedures were performed in accordance with protocols approved by the University of Arizona institutional animal care and use committee.

Intracardiac injections procedures were performed by the same person, Bethany Skovan, of the Experimental Mouse Shared Service of the Arizona Cancer Center. Mice were anesthetized with isoflurane (2-3\% delivered through a nose cone). Injections were performed using a $27 \mathrm{~g}$ needle and injected into the left ventricle of the heart between the $3^{\text {rd }}$ and $4^{\text {th }}$ or between the $4^{\text {th }}$ and $5^{\text {th }}$ intracostal space as previously described by others [15]. The presence of bright red arterial blood indicated that the needle was properly placed. Approximately $0.5 \times 10^{6}$ cells in $0.2 \mathrm{ml}$ of PBS containing $\mathrm{Ca}^{++}, \mathrm{Mg}^{++}$were injected. Twelve mice per group received a single injection to avoid excessive damage to the heart. Mice were allowed to recover from anesthesia and observed for any odd behavior. Mice with incorrectly placed injections as judged by early death or presence of chest tumor at necropsy were removed from the study. Accordingly, a range of six to eight mice per group are reported in Table $\mathbf{1}$ and seven to eight mice per group are reported in Fig. (3).

\section{Radiographic Imaging}

Animals were anesthetized with ketamine- $\mathrm{HCl}$ (50mg/ $\mathrm{kg}$ ) and xylazine $(15-20 \mathrm{mg} / \mathrm{kg})$. Radiographs were taken 3 , 4, 5 and 6 weeks after tumor cell injection using a Faxitron MX-20 machine at $7 \mu \mathrm{M}$ nominal resolution with an X-ray current of $300 \mathrm{uA}$ and a voltage of $26 \mathrm{kV}$ (Faxitron X-ray Corp., Wheeling, IL). Each digital image requires 10 seconds. Animals were allowed to recover from anesthesia and returned to the animal care facility. Images were read and interpreted by G.D.P. (board certified radiologist) without knowledge of the treatment groups.

Table 1. Radiographic Detection of Metastasis

\begin{tabular}{|c|c|c|c|c|}
\hline PC-3 Cells & 3 Weeks & 4 Weeks & 5 Weeks & 6 Weeks \\
\hline 1 & Normal & Normal & Normal & Normal \\
\hline 2 & Normal & Normal & LPT, LPH & LPT, LPH \\
\hline 3 & Normal & Normal & Normal & Normal \\
\hline 5 & Normal & Normal & Normal & Normal \\
\hline 6 & Normal & Normal & Normal & Normal \\
\hline PC-3B1 Cells & 3 Weeks & 4 Weeks & 5 Weeks & 6 Weeks \\
\hline \multicolumn{5}{|l|}{ Mouse } \\
\hline 9 & Normal & Normal & LPT & LPT \\
\hline 10 & RMT & RMT, RMF & RMT, RMF, RDT & RMT, RMF, RDT \\
\hline 11 & RMT & RMT, RPT & RPT, RMT, RDT, LPT & $*$ Terminated \\
\hline 12 & Normal & Normal & LPT & LPT \\
\hline 13 & RPT & $\begin{array}{l}\text { RPT, LPF } \\
\text { LPU }\end{array}$ & $\begin{array}{c}\text { RPT, RMT, LDT, LPF } \\
\text { RPH, LPH, LPU }\end{array}$ & *Terminated \\
\hline 14 & LPT & LPT & LPT, RDF, RPT, RPH & LPT, RDF, RPT, RPH \\
\hline
\end{tabular}

Code: $\mathrm{LPT}=$ left proximal tibia; $\mathrm{LPH}=$ left proximal humerus; $\mathrm{LDT}=$ left distal tibia; $\mathrm{LPF}=$ left proximal fibula; $\mathrm{LPU}=$ left proximal ulna; $\mathrm{RPH}=$ right proximal humerus; $\mathrm{RMF}=$ right mid femur; $\mathrm{RMT}=$ right mid tibia; $\mathrm{RDT}=$ right distal tibia; RPT $=$ right proximal tibia.

* Mice were terminated according to study protocol to prevent development of severe fractures. 


\section{Histological Analysis}

At the end of the study, animals were euthanized via $\mathrm{CO}_{2}$ inhalation. Organs were harvested and processed by the Arizona Cancer Center core service for tissue acquisition and molecular analysis (TACMASS). Tissues were harvested, fixed in $10 \%$ neutral buffered formalin for 24 hours, processed and embedded in paraffin. Routine hematoxylin and eosin $(\mathrm{H} \& \mathrm{E})$ stains were performed on three micron sections of tissue cut from the formalin fixed, paraffin embedded (FFPE) blocks. Hematoxylin counterstaining was performed on the Discovery XT Automated Immunostainer (Ventana Medical Systems, Inc. (VMSI), Tucson AZ) instrument using VMSI validated reagents. Following staining on the instrument, slides were dehydrated through graded alcohols to xylene and coverslipped with Pro-Texx mounting medium. Images were captured using an Olympus BX50 and Spot (Model 2.3.0) camera. Images were standardized for light intensity.

\section{DASL Array Gene Expression Analysis}

Total RNA was isolated from PC-3 or PC-3B1 cells following multiple passages in standard cell culture conditions. The isolated RNA was quantified by UV spectroscopy using the NanoDrop 1000 (NanoDrop technologies, Inc., DE) and subjected to cDNA-mediated annealing, selection, extension and ligation assay (DASL) gene expression analysis (Illumina, Inc.). Agilent BioAnalyzer traces were also conducted using the RNA Nano 6000 series II Lab Chip (Agilent Inc.) to assess overall RNA quality. Illumina's DASL is a gene assay designed to generate expression profiles. The DASL assay was used with the standard human cancer panel from Illumina and with the universal 16 bead chip. The assay was performed according to standard Illumina protocols (Illumina Bead Station DASL System Manual). Briefly, the human cancer panel from Illumina comprises a pool of selected probes groups for 502 unique cancer gene mRNAs, each mRNA being targeted in three locations by separate probes. For each sample, input quantity for the reaction was normalized to $200 \mathrm{ng}$ ( $5 \mathrm{ul}$ at $40 \mathrm{ng} / \mathrm{ul}$ ). This was converted into cDNA using biotinylated random nanomers, oligo-deoxythymidine 18 primers and Illumina supplied reagents according to manufacturer instructions. The resulting biotinylated cDNA was annealed to assay oligonucleotides and bound to strepavidin-conjugated paramagnetic particles to select cDNA/oligo complexes. After oligo hybridization, mis-hybridized and nonhybridized oligos were washed away, while bound oligos were extended and ligated to generate templates to be subsequently amplified with shared PCR primers. The fluorescently labeled complementary strand was hybridized as per standard protocols to a universal DASL 16x1 Bead Chip. The universal 16 Bead chip platform is composed of 16 individual arrays and for each sample three technical replicates were performed. After hybridization, the arrays were scanned using the Illumina Bead Array reader 500 system.

\section{Real-Time PCR}

Total RNA was isolated from PC-3 and PC-3B1 cells and reverse transcribed into cDNA. Taqman Gene Expression ${ }^{\circledR}$ probes for AXL (Hs00242357_m1), CD34 (Hs00156373_m1),
CDH11 (Hs00156438_m1), MET (Hs01565584_m1) and the reference gene human ACTB (beta actin) were purchased from Applied Biosystems (Foster City, CA). Real-time PCR was performed using a Roche Lightcycler calibrated using human reference total RNA (Applied Biosystems) and the relative expression of each target gene was generated with the Roche Lightcycler 480 II software. Expression levels of each gene were normalized to the reference gene $\mathrm{ACTB}$ prior to determining the fold change of PC-3B1 to PC-3 cells.

\section{Flow Cytometry}

The prostate cells were harvested using $5 \mathrm{mM}$ EDTA in PBS, washed once in PBS and then resuspended in $200 \mu \mathrm{L}$ of $0.2 \% \mathrm{BSA} / \mathrm{PBS}$ containing primary antibody (1:200) for the $\alpha 6$ specific rat mAb J1B5 generated by Dr. Caroline Damsky [18]. All antibody incubations were performed for 30 minutes on ice. Primary antibody binding was detected by Alexa 488 anti-rat secondary antibody (1:1000) and analyzed using the Flow Cytometry Service of the Arizona Cancer Center.

\section{Immunocytochemistry}

The prostate cancer cells were grown on glass coverslips overnight, rinsed in PBS and fixed using ice cold 100\% methanol for 10 minutes followed by dipping in $100 \%$ acetone. Non-specific binding was blocked using $2 \%$ BSA in PBS. The mouse monoclonal cytokeratin 10.11 (CK10.11) antibody was a gift from Dr. Robert Cardiff, (University of California, Davis, CA) and was used at 1:800 for 30 minutes at room temperature. Primary antibody binding was detected by Alexa Fluor 568 donkey anti-mouse secondary antibody (1:600) for 30 minutes at room temperature. The coverslips were mounted onto slides using Prolong Antifade reagent from Invitrogen (Carlsbad, CA) and images were collected using a Zeiss Axiophot (Carl Zeiss, Gottingen, Germany) equipped with an Axiocam camera.

\section{Statistical Analysis}

Gene expression data obtained from the DASL array was tested for significant differences between PC-3 and PC-3B1 human prostate tumor cells using a heteroskedastic t-test following normalization using Illumina ${ }^{\circledR}$ software.

\section{RESULTS}

\section{Radiographic Imaging of Xenograft Tumor Growth}

Injection of isolated human prostate cancer PC-3B1 cells into SCID mice in separate trials resulted in reproducible in vivo bone homing of the cell line. The PC-3B1cells were obtained previously by isolation from the bone marrow of SCID mice that had been injected six weeks previously with the PC-3 cell line, as described in the Methods. The PC-3B1 and parental PC-3 cells express the epithelial cell marker integrin $\alpha 6$ as determined by flow cytometry and cytokeratins as determined by immunocytochemistry (Fig. 1). Digital radiographic images of tumor growth in skeletal regions of live SCID mice were taken at 3, 4, 5 and 6 weeks post intracardiac injection of prostate cancer PC-3B1 cells. Fig. (2) represents the presence of osteolytic activity near the epiphyseal plate as early as 4 weeks post injection. The lesions 
A

B
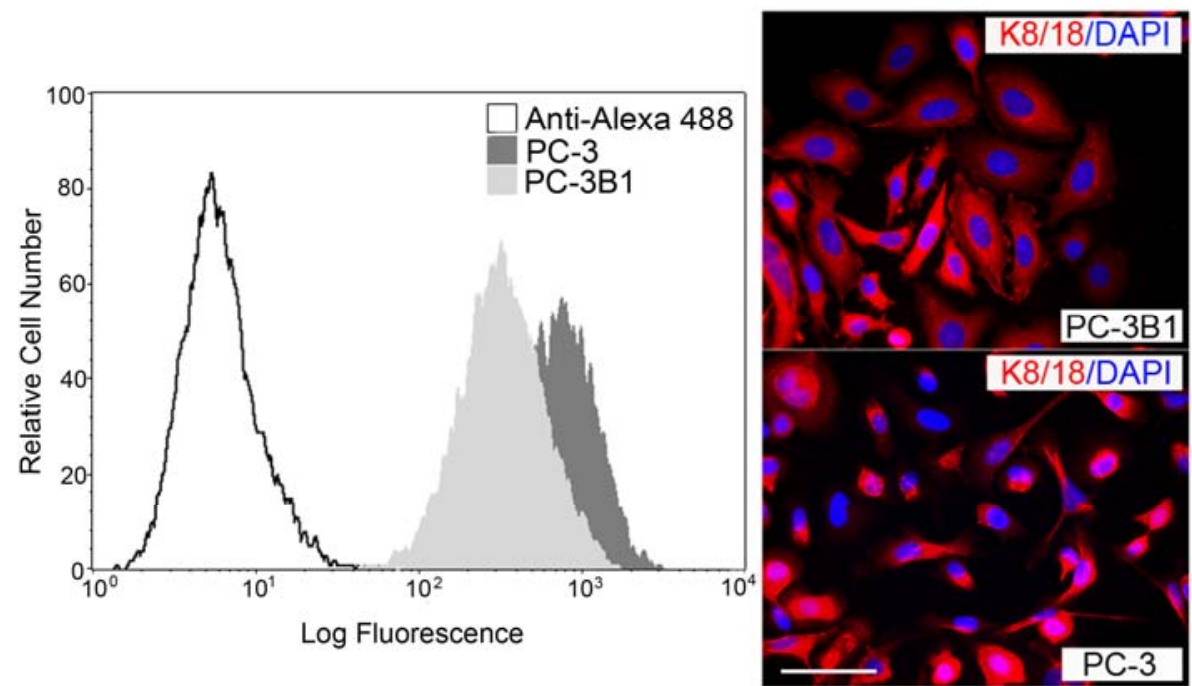

Fig. (1). Epithelial markers in PC-3 and PC-3B1 cells. (A) PC-3 and PC-3B1 cells were analyzed by flow cytometry for cell surface expression of the $\alpha 6$ integrin. (B) PC-3B1 cells (top panel) and PC-3 cells (bottom panel) were analyzed using immunohistochemical detection of cytokeratins 8 and $18(\mathrm{~K} 8 / 18)$. Scale bar $=100 \mu \mathrm{m}$.

were progressive and the increased bone loss by 5 and 6 weeks resulted in termination of the animals prior to the development of severe fractures, as dictated by protocol. Tumor growth characteristics through standard radiographic imaging was documented in mice injected with PC-3 cells (mice 1-6) or PC-3B1 cells (mice 7-14). Table 1 indicates the early onset of skeletal metastasis in PC-3B1 cells as compared to PC-3 cells. At 3 and 4 weeks post tumor cell injection, mice injected with PC-3 cells did not have detectable skeletal metastases while $5 / 8$ (62.5\%) of mice injected with PC-3B1 cells had lesions in skeletal regions as indicated in Table 1. The number of mice injected with PC3B1 cells with detectable skeletal metastases at 5 and 6 weeks was significantly higher than PC-3 injected mice, 7/8 $(87.5 \%)$ mice and $2 / 6(33 \%)$ mice, respectively. Furthermore, mice 11 and 13 injected with PC-3B1 cells developed micro fractures by 5 weeks and were terminated at 6 weeks prior to frank fractures as dictated by the study protocol. The distribution of skeletal metastases in mice injected with PC$3 \mathrm{~B} 1$ cells at 3 weeks was predominantly localized to one or two major regions, but bone lesions increased in prevalence in multiple areas by 4,5 and 6 weeks as noted in Table 1.

\section{Xenograft Tumor Growth}

We next determined the metastatic fate of the PC-3B1 cells in selected organs other than the bone. A group of eight or seven animals were successfully injected with either PC-3 or PC-3B1 cells, respectively. Fig. 3 shows histological appearance of PC-3B1 metastases in formalin fixed paraffin embedded mouse tissues at 6 weeks post intracardiac injection. Although some metastatic lesions were detected in the adrenal gland (Fig. 3A) and liver (Fig. 3B), metastatic lesions predominated in the femur (Fig. 3C) and tibia (Fig. 3D). Histological assessment of metastatic regions of mice injected with either PC-3 or PC-3B1 cells shown in Fig. (3E) indicates that $3 / 8(37.5 \%)$ of PC-3 injected mice had adrenal metastasis and $2 / 8(25 \%)$ harbored bone lesions. In contrast, mice injected with PC-3B1 cells had 2/7 (28.6\%) mice with liver metastases, $6 / 8(85.7 \%)$ with adrenal gland metastases and $6 / 7(87.5 \%)$ with bone lesions. It is important to note that one mouse injected with PC-3B1 cells developed a large primary tumor in the cardiac region of the animal resulting from inappropriate injection. There was no evidence of detectable metastases in the heart, lung or kidneys in either group with accurate injections.

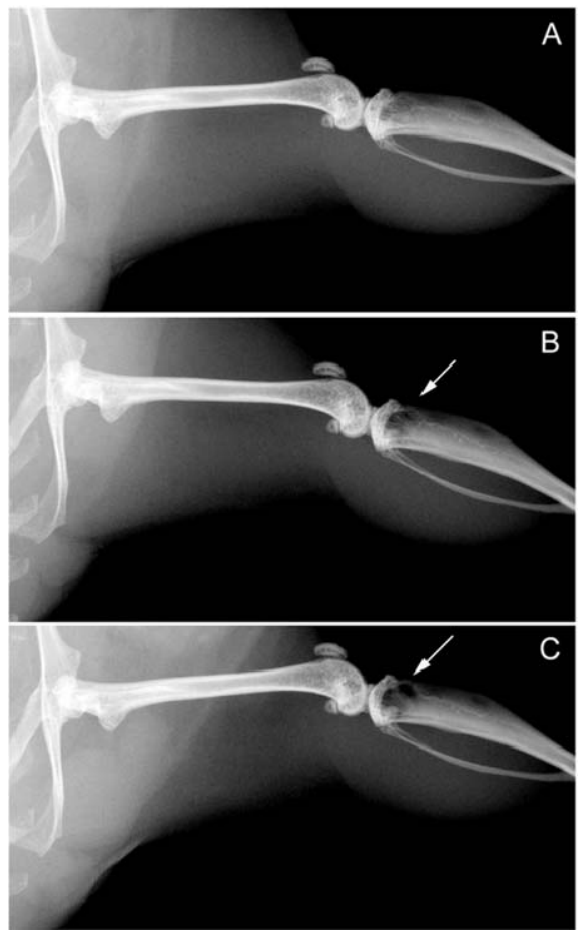

Fig. (2). Progressive bone metastatic lesions were detected by digital radiographs. Digital radiographic images of tumor growth in skeletal regions of live SCID mice were taken at (A) four, (B) five, and (C) six weeks post intracardiac injection of prostate cancer PC-3B1 cells. The presence of osteolytic activity near the epiphyseal plate is apparent at 4 weeks post injection and increases in severity at 5 and 6 weeks (arrows). 


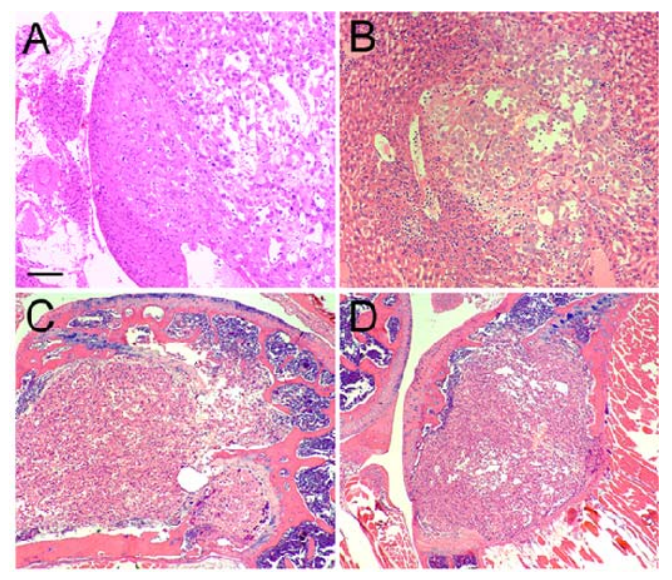

E

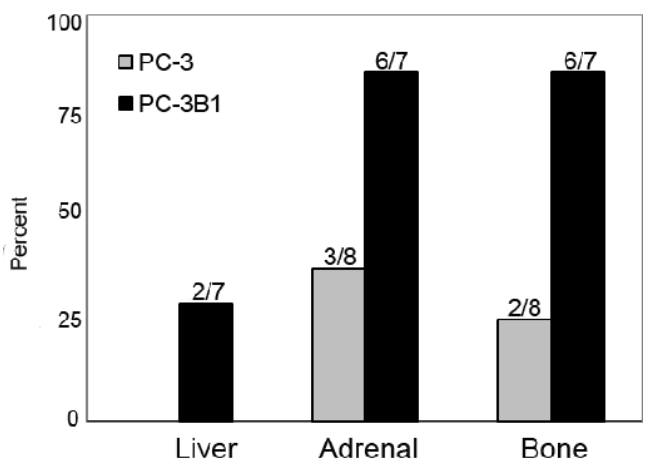

Fig. (3). Histological detection of metastatic lesions. Six weeks post intracardiac injection of PC-3B1 cells, the mouse organs were harvested and processed for $\mathrm{H}$ and $\mathrm{E}$ staining. (A) Metastasis in the medullary portion of adrenal gland, (B) Liver with expanding metastasis, (C) Metastasis in head of femur with destruction of epiphyseal plate, (D) Metastasis in head of tibia showing erosion to the bone surface. Bar equals 100 microns. Part (E) indicates the percentage of mice per group with metastatic lesions in the liver, adrenal or bone. Seven mice were successfully injected with PC3B1 cells and 8 mice were successfully injected with PC-3 cells.

\section{Bone Trophic Prostate Tumor Cell Gene Transcription Analysis}

As stated earlier, the goal was to identify molecular imaging candidates based upon three criteria, one of which was increased expression in bone trophic tumor cells. We utilized a comparative analysis of the DASL gene expression assay for parental PC-3 cells and PC-3B1 cells grown in tissue culture conditions following isolation from mouse bone lesions. The complete expression array results are detailed in Supplementary Fig. (1). The primary data was screened to determine genes that showed at least a 1.5 fold increase in expression in the PC-3B1 cells as compared to the PC- 3 cells. The analysis revealed 55 genes with 1.5 fold or higher expression in PC-3B1 cells. The next two criteria (membrane receptors and expressed in human tumors) were applied and Table 2 lists four specific genes that fit the criteria. Fig. (4) shows quantitative real-time RT-PCR results confirming the DASL array results for fold changes in AXL, $\mathrm{CDH} 11, \mathrm{CD} 34$ and MET in PC-3B1 cells when compared to PC-3 cells. We note with interest that the majority of the increased genes expressed in the more aggressive bone trophic line are normally considered hematopoietic rather than epithelial markers. This data is consistent with previous reports in that metastatic tumor cells undergo adaptation to their environment and the adaptation is a stable phenotype since these cells were passaged in tissue culture after retrieval from the mouse bone marrow [19].

\section{DISCUSSION}

Our study demonstrates a reproducible prostate cancer bone xenograft metastasis model using a bone trophic cell line (PC3-B1) established from intracardiac injection of human PC-3 prostate cancer cells into SCID mice. The human PC-3B1 bone trophic cell line exhibits a bone homing phenotype since six of seven animals developed prominent skeletal lesions as compared to two of eight using PC-3 cells. Previously developed mouse xenograft intracardiac injection models have produced skeletal metastases varying from two of seven mice injected with LNCaP C4-2 cells to two of three mice injected with PC-3 cells [16, 20, 21]. Our results correspond with these studies in that PC-3 cell injection produced low but reproducible levels of total skeletal metastases with only two out of eight mice developing lesions. In contrast, the PC-3B1 cell line demonstrated effective bone homing characteristics and six out of seven animals developed prominent skeletal lesions.

The bone lesions in PC-3B1 mice were analyzed using digital radiographic imaging and were detected as early as three weeks post intracardiac injection. These skeletal lesions in prominent long bones including the tibia and femur and to a lesser extent the ulna, fibula and humerus, presented with substantial bone loss in the trabecular bone. Over time, the skeletal lesions became increasingly higher in number with greater bone loss up to six weeks post injection. Mice with significant bone degradation exhibited micro fractures in the fifth week of the study and were terminated according to the protocol to avoid anticipated fractures at six weeks.

The altered and fragile bone environment exhibited in our model has clinical implications in that patients with highly invasive human prostate tumor cells will commonly harbor bone metastatic lesions. The presence of prostate tumor cells in patient bone and their growth produces a fragile environment likely leading to severe fracturing. This propensity to develop fractures with resultant incapacitating pain leads to decreased quality of life and increased risk of mortality for these patients.

Understanding the mechanisms mediating prostate tumor cell metastasis to bone is essential for developing specific and sensitive screening techniques to identify metastatic lesions in bone. Clinical and experimental observations indicate that hematopoietic marrow, rather than bone tissue is the initial site of cancer cell seeding [22, 23]. However, bone marrow micrometastases often elude radiographic detection commonly used to stage prostate cancer [4]. Increasing knowledge of cell biology based mechanisms of prostate tumor bone homing and establishment of microme- 
Table 2. Increased Expression of Genes* Encoding Transmembrane Proteins in Bone Trophic Human Prostate Cells on DASL Array

\begin{tabular}{|c|c|c|c|}
\hline Gene & Fold Change & P-value & Expression and Function \\
\hline AXL & 3.4 & $5.7 \times 10^{-5}$ & $\begin{array}{l}\text { Receptor tyrosine kinase, } 98.3 \mathrm{KDa} \text {. Epithelial, macrophage marker, bone marrow stromal } \\
\text { cells [26]. Activates signaling cascades to regulate adhesion, migration, } \\
\text { phagocytosis and survival in tumorigenesis }[38,39]\end{array}$ \\
\hline CDH11 & 1.6 & $4.5 \times 10^{-2}$ & $\begin{array}{c}\text { Cadherin 11,76.5 KDa. Calcium-dependent adhesion in bone development and maintenance } \\
{[28] \text { and induction of neurite outgrowth [40] overexpressed in osteosarcoma }}\end{array}$ \\
\hline CD34 & 1.5 & $8.0 \times 10^{-3}$ & Hematopoietic progenitor cells/cell surface antigen $[24,25], 110 \mathrm{KDa}$ \\
\hline MET & 2.0 & $1.3 \times 10^{-3}$ & $\begin{array}{c}\text { Hepatocyte growth factor receptor, } 157.7 \mathrm{KDa} \text {. Mesenchymal cells, bone marrow stromal } \\
\text { cells [27, 29]. Regulates hemopoeisis [41]. Stimulates proliferation, migration, } \\
\text { morphogenesis and bone metastasis [42] }\end{array}$ \\
\hline
\end{tabular}

*Gene expression increased in PC3-B1 cells over 1.5 fold compared to PC-3 cells.

tastases in bone marrow through laboratory based discoveries may provide new targets for radiological imaging. This model also results in a consistent pattern of adrenal metastasis which may be useful for investigating hormonal influence and cancer progression.

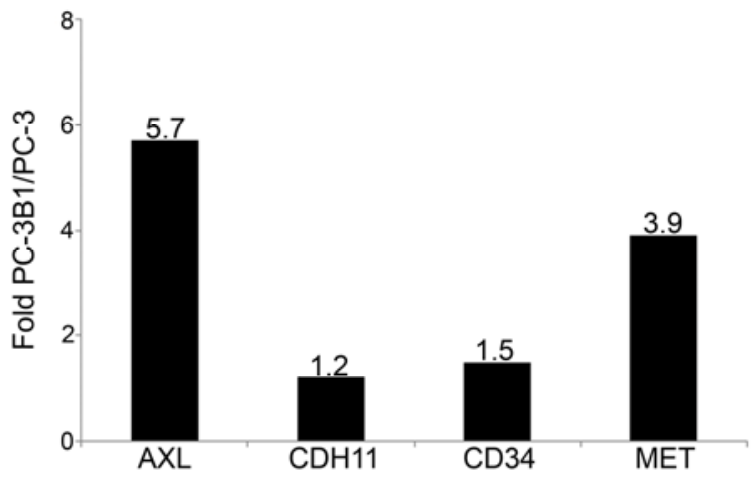

Fig. (4). Increased mRNA expression of genes encoding transmembrane proteins in bone trophic human prostate cells. Real time RT-PCR was performed using probes specific for MET, CD34, CDH11 and AXL to confirm DASL array analysis on PC-3 and bone trophic PC-3B1 cells. The results are reported as fold change expression of PC-3B1 cells compared to PC-3 cells and are representative of three independent experiments.

We analyzed the transcription signatures from a restricted set of genes for both the PC-3 and PC-3B1 cells and found 55 genes with 1.5 fold or higher expression in PC-3B1 cells. Within this group, four of the genes encode proteins with cell surface expression. These proteins are likely candidates for molecular imaging using nanoparticle imaging since cell surface receptors have previously been utilized for this technology [8-10]. Interestingly, the identified cell surface molecules on the PC-3B1 cells (AXL, CDH11, CD34, and MET) are proteins expressed within cell types of hematopoietic origin [24-29]. Other groups have reported that metastasizing cancer cells adopt many of the properties of hematopoietic cells to establish themselves in bone [30, 31]. The bone trophic PC-3B1 cell population expresses surface proteins normally present on hematopoietic cells and may mimic the residency requirements of the bone marrow niche. We note that residency in bone from the circulation occurs within 1 to $2 \mathrm{~h}$ of intracardiac injection [22, 32, 33]. Coincident expression of hematopoietic and epithelial markers on a bone resident tumor may be a useful anomaly for early detection. The aberrant co-incident expression of both hematopoietic and epithelial receptors on tumor cells opens the possibility of using multi-plexing imaging technology to specifically detect micro metastases in bone.

Previous studies and this model demonstrate predominantly osteolytic bone lesion development following intracardiac injection $[16,21]$ of the human PC-3 cell line which is one of the few commercially available prostate tumor cell lines that was directly isolated from a patient bone metastasis [34]. These lesions only partially mimic the clinical manifestation of prostate tumor bone lesions, which are often both osteolytic and osteoblastic in character [35]. The short six week time course of this study may play a role in our inability to identify both osteolytic and osteoblastic responses, which has also been observed by other investigators using the PC-3 cell intracardiac injection model [16, 36]. For example, severe fracturing in mice occurring by six weeks may precede a secondary osteoblastic response which could not be evaluated by us due to animal termination as specified by the protocol. It is important to note that bone lesions of mice injected with bone trophic prostate tumor cells were predominantly located in highly metabolic regions. This localization mimics the distribution of lesions in highly metabolic areas of bone in human prostate cancer patients and highlights the use of the model in establishing specific bone trophic characteristics of metastasizing human prostate tumor cells. However, we note that significant limitations of the model include the lack of bone metastases in the axial skeleton, the lack of osteoblastic lesions, the lack of an immune response in the animal and the bolus injection of tumor cells within the circulation.

In summary, we have developed a prostate cancer bone trophic cell line from a highly reproducible bone metastasis xenograft model. We have also identified a distinct transcriptional signature encoding cell surface gene products, specific for bone trophic prostate tumor cells. Four cell 
surface molecules with known expression in human tumors may be significant targets for prostate bone metastasis imaging. The identification of a mixed hematopoietic and epithelial cell surface phenotype may be useful for detection of pro-metastastic cancer cells as predicated by earlier studies [37].

\section{ACKNOWLEDGEMENT}

The work was supported by NIH grants CA23752 and CA56666. Authors have no financial relationship to disclose.

\section{SUPPLEMENTARY MATERIAL}

Supplementary material is available on the publishers Web site along with the published article.

\section{REFERENCES}

[1] Massoud TF, Gambhir SS. Integrating noninvasive molecular imaging into molecular medicine: an evolving paradigm. Trends Mol Med 2007; 13(5): 183-91.

[2] Kurhanewicz J, Vigneron D, Carroll P, Coakley F. Multiparametric magnetic resonance imaging in prostate cancer: present and future. Curr Opin Urol 2008; 18(1): 71-7.

[3] Choi YJ, Kim JK, Kim N, Kim KW, Choi EK, Cho KS. Functional MR imaging of prostate cancer. Radiographics 2007; 27(1): 63-75, discussion 75-7.

[4] Margolis DJ, Hoffman JM, Herfkens RJ, Jeffrey RB, Quon A, Gambhir SS. Molecular imaging techniques in body imaging. Radiology 2007; 245(2): 333-56.

[5] Huzjan R, Sala E, Hricak H. Magnetic resonance imaging and magnetic resonance spectroscopic imaging of prostate cancer. Nat Clin Pract Urol 2005; 2(9): 434-42.

[6] Serda RE, Adolphi NL, Bisoffi M, Sillerud LO. Targeting and cellular trafficking of magnetic nanoparticles for prostate cancer imaging. Mol Imaging 2007; 6(4): 277-88.

[7] Wang AZ, Bagalkot V, Vasilliou CC, et al. Superparamagnetic iron oxide nanoparticle-aptamer bioconjugates for combined prostate cancer imaging and therapy. ChemMedChem 2008; 1311-15.

[8] Funovics M, Montet X, Reynolds F, Weissleder R, Josephson L. Nanoparticles for the optical imaging of tumor E-selectin. Neoplasia 2005; 7(10): 904-11.

[9] Funovics MA, Kapeller B, Hoeller C, et al. MR imaging of the her2/neu and 9.2.27 tumor antigens using immunospecific contrast agents. Magn Reson Imaging 2004; 22(6): 843-50.

[10] Montet X, Montet-Abou K, Reynolds F, Weissleder R, Josephson L. Nanoparticle imaging of integrins on tumor cells. Neoplasia 2006; 8(3): 214-22.

[11] Schmelz M, Cress AE, Scott KM, et al. Different phenotypes in human prostate cancer: alpha6 or alpha3 integrin in cellextracellular adhesion sites. Neoplasia 2002; 4(3): 243-54.

[12] Davis TL, Rabinovitz I, Futscher BW, et al. Identification of a novel structural variant of the alpha 6 integrin. J Biol Chem 2001; 276(28): 26099-106.

[13] Pawar PSC, Demetriou MC, Nagle RB, Bowden GT, Cress AE. Integrin alpha6 cleavage: a novel modification to modulate cell migration. Exp Cell Res 2007; 313(6): 1080-9.

[14] Ports MO, Nagle RB, Pond GD, Cress AE. Extracellular engagement of alpha6 integrin inhibited urokinase-type plasminogen activator-mediated cleavage and delayed human prostate bone metastasis. Cancer Res 2009; 69(12): 5007-14.

[15] Arguello F, Baggs RB, Frantz CN. A murine model of experimental metastasis to bone and bone marrow. Cancer Res 1988; 48(23): 6876-81.

[16] Wu TT, Sikes RA, Cui Q, et al. Establishing human prostate cancer cell xenografts in bone: induction of osteoblastic reaction by prostate-specific antigen-producing tumors in athymic and SCID/ bg mice using LNCaP and lineage-derived metastatic sublines. Int $\mathrm{J}$ Cancer 1998; 77(6): 887-94.
[17] Sroka IC, Nagle RB, Bowden GT. Membrane-type 1 matrix metalloproteinase is regulated by sp1 through the differential activation of AKT, JNK, and ERK pathways in human prostate tumor cells. Neoplasia 2007; 9(5): 406-17.

[18] Damsky $\mathrm{CH}$, Librach C, Lim KH, et al. Integrin switching regulates normal trophoblast invasion. Development 1994; 120(12): 3657-66.

[19] Minn AJ, Gupta GP, Siegel PM, et al. Genes that mediate breast cancer metastasis to lung. Nature 2005; 436(7050): 518-24.

[20] Thalmann GN, Anezinis PE, Chang SM, et al. Androgenindependent cancer progression and bone metastasis in the LNCaP model of human prostate cancer. Cancer Res 1994; 54(10): 257781.

[21] Yang M, Jiang P, Sun FX, et al. A fluorescent orthotopic bone metastasis model of human prostate cancer. Cancer Res 1999; 59(4): 781-6.

[22] Wetterwald A, van der Pluijm G, Que I, et al. Optical imaging of cancer metastasis to bone marrow: a mouse model of minimal residual disease. Am J Pathol 2002; 160(3): 1143-53.

[23] Wong KF, Chan JK, Ma SK. Solid tumour with initial presentation in the bone marrow--a clinicopathologic study of 25 adult cases. Hematol Oncol 1993; 11(1): 35-42.

[24] Bullock TE, Wen B, Marley SB, Gordon MY. Potential of CD34 in the regulation of symmetrical and asymmetrical divisions by hematopoietic progenitor cells. Stem Cells 2007; 25(4): 844-51.

[25] Okuno Y, Iwasaki H, Huettner CS, et al. Differential regulation of the human and murine CD34 genes in hematopoietic stem cells. Proc Natl Acad Sci USA 2002; 99(9): 46-51.

[26] Satomura K, Derubeis AR, Fedarko NS, et al. Receptor tyrosine kinase expression in human bone marrow stromal cells. J Cell Physiol 1998; 177(3): 426-38.

[27] Son BR, Marquez-Curtis LA, Kucia M, et al. Migration of bone marrow and cord blood mesenchymal stem cells in vitro is regulated by stromal-derived factor-1-CXCR4 and hepatocyte growth factor-c-met axes and involves matrix metalloproteinases. Stem Cells 2006; 24(5): 1254-64.

[28] Tamura D, Hiraga T, Myoui A, Yoshikawa H, Yoneda T. Cadherin11-mediated interactions with bone marrow stromal/osteoblastic cells support selective colonization of breast cancer cells in bone. Int J Oncol 2008; 33(1): 17-24.

[29] Wang PP, Wang JH, Yan ZP, et al. Expression of hepatocyte-like phenotypes in bone marrow stromal cells after HGF induction. Biochem Biophys Res Commun 2004; 320(3): 712-6.

[30] Shiozawa Y, Havens AM, Jung Y, et al. Annexin II/Annexin II receptor axis regulates adhesion, migration, homing, and growth of prostate cancer. J Cell Biochem 2008; 105(2): 370-80.

[31] Shiozawa Y, Havens AM, Pienta KJ, Taichman RS. The bone marrow niche: habitat to hematopoietic and mesenchymal stem cells, and unwitting host to molecular parasites. Leukemia 2008; 22(5): 941-50.

[32] Harms JF, Welch DR. MDA-MB-435 human breast carcinoma metastasis to bone. Clin Exp Metastasis 2003; 20(4): 327-34.

[33] Phadke PA, Mercer RR, Harms JF, et al. Kinetics of metastatic breast cancer cell trafficking in bone. Clin Cancer Res 2006; 12(5): 1431-40.

[34] Kaighn ME, Narayan KS, Ohnuki Y, Lechner JF, Jones LW. Establishment and characterization of a human prostatic carcinoma cell line (PC-3). Invest Urol 1979; 17(1): 16-23.

[35] Guise TA, Mohammad KS, Clines G, et al. Basic mechanisms responsible for osteolytic and osteoblastic bone metastases. Clin Cancer Res 2006; 12(20 Pt 2): 6213s-6s.

[36] Hsu WK, Virk MS, Feeley BT, Stout DB, Chatziioannou AF, Lieberman JR. Characterization of osteolytic, osteoblastic, and mixed lesions in a prostate cancer mouse model using 18F-FDG and 18F-fluoride PET/CT. J Nucl Med 2008; 49(3): 414-21.

[37] Coman DR. Mechanisms responsible for the origin and distribution of blood-borne tumor metastases: a review. Cancer Res 1953; 13(6): 397-404.

[38] Hafizi S, Dahlback S. Signalling and functional diversity within the Axl subfamily of receptor tyrosine kinases. Cytokine Growth Factor Rev 2006; 17(4): 295-304. 
[39] Linger RM, Keating AK, Earp HS, Graham DK. TAM receptor tyrosine kinases: biologic functions, signaling, and potential therapeutic targeting in human cancer. Adv Cancer Res 2008; 100: 3583.

[40] Boscher C, Mege RM. Cadherin-11 interacts with the FGF receptor and induces neurite outgrowth through associated downstream signalling. Cell Signal 2008; 20(6): 1061-72.
[41] Ikehara S. Role of hepatocyte growth factor in hemopoiesis. Leuk Lymphoma 1996; 23(3-4): 297-303.

[42] Ono K, Kamiya S, Akatsu T, et al. Involvement of hepatocyte growth factor in the development of bone metastasis of a mouse mammary cancer cell line, BALB/c-MC. Bone 2006; 39(1): 27-34.

Received: January 5, 2009

Revised: July 3, 2009

Accepted: July 7, 2009

C). Sroka et al.; Licensee Bentham Open.

This is an open access article licensed under the terms of the Creative Commons Attribution Non-Commercial License (http://creativecommons.org/licenses/ by-nc/3.0/) which permits unrestricted, non-commercial use, distribution and reproduction in any medium, provided the work is properly cited. 